\title{
ANALISIS KETERAMPILAN SOSIAL MENGGUNAKAN FIRO-B PADA AUDITOR INTERNAL PEMERINTAH DI PROVINSI BENGKULU
}

\author{
ANALYSIS OF SOCIAL SKILLS USING FIRO-B GOVERNMENT INTERNAL \\ AUDITORS IN BENGKULU PROVINCE
}

\author{
Lismawati $^{1)}$ dan Emilyan Inzar ${ }^{2)}$ Jaka Isgiyarta $^{3)}$ Novita Sari $^{4}$ \\ Fakultas Ekonomi Dan Bisnis Universitas Bengkulu ${ }^{1,2,4)}$ \\ Fakultas Ekonomi Dan Bisnis Universitas Diponegoro ${ }^{3)}$
}

\begin{abstract}
This study aims to analyze and prove whether there are differences in the level of social skills of internal auditors in terms of culture, gender and age. This study uses an internal auditor working in the Bengkulu Provincial Audit Board (BPKP) as a sample. Data were analyzed using the Fundamental Interation Relationship-Behavior (FIRO-B) score and independent sample t-test with the SPSS program. The results showed that there were no significant differences in the level of social skills between the internal auditors of different cultures, genders and ages of the internal auditors working in the Bengkulu Province Audit Board $(B P K P)$. The results of this study provide research evidence that there is no difference in the ability of social skills in terms of cultural, gender and age differences.
\end{abstract}

Key words: social skills, cultures, genders, ages, internal auditors

\begin{abstract}
ABSTRAK
Penelitian ini bertujuan untuk menganalisis dan membuktikan apakah ada perbedaan tingkat keterampilan sosial auditor intern dilihat dari sisi budaya, jenis kelamin dan usia. Penelitian ini menggunakan auditor intern yang bekerja di Badan Pemeriksa Keuangan (BPKP) Provinsi Bengkulu sebagai sampel. Data dianalisis menggunakan skor Fundamental Interation Relation Orientation-Behavior (FIRO-B) dan independent sample t-test dengan program SPSS. Hasil penelitian menunjukkan bahwa tidak ada perbedaan yang signifikan dalam tingkat keterampilan sosial antara auditor internal dari budaya, jenis kelamin dan usia yang berbeda pada auditor intern yang bekerja di Badan Pemeriksa Keuangan (BPKP) Provinsi Bengkulu. Hasil penelitian ini memberikan bukti riset terkait tidak ada perbedaan terhadap kemampuan keterampilan sosial dari sisi perbedaan budaya, jenis kelamin dan usia.
\end{abstract}

Kata kunci: keterampilan sosial, budaya, Jenis kelamin, usia, auditor internal

Corresponding author: Lismawati390@ gmail.com ${ }^{1)}$

Email : Lismawati390@gmail.com ${ }^{1)}$, ceritasukses9@gmail.com ${ }^{2}$

DOI : https://doi.org/10.33369/j.akuntansi.9.3.115-128

\section{PENDAHULUAN}

Keterampilan sosial merupakan kemampuan seseorang dalam mengadakan hubungan dengan orang lain dan kemampuan memecahkan masalah, sehingga dapat beradaptasi secara harmonis dengan masyarakat disekitarnya. Keterampilan sosial dimulai dari adanya sikap saling menyadari keberadaan satu dengan yang lain kemudian adanya kontak antar pribadi. Di dalam membangun dan menciptakan hubungan, terjadi proses interaksi dan komunikasi. Dalam proses tersebut individu menginginkan suasana yang dapat menciptakan keharmonisan, sehingga hubungan yang baik dapat tercapai (Izzati,2014). 
Pentingnya keterampilan sosial bagi setiap individu disebabkan individu adalah makhluk sosial yang saling berinteraksi dalam berbagai hal. Interaksi dilakukan untuk saling memenuhi kebutuhan masing-masing dan dapat hidup dengan nyaman. Agar interaksi berjalan dengan baik diperlukan keterampilan sosial. Keterampilan sosial memiliki peran penting dalam hidup setiap individu. Individu dengan keterampilan sosial yang tinggi memiliki lingkungan pergaulan yang baik, disukai banyak orang, mampu mengendalikan diri, mampu menyampaikan ide dengan baik, berdiskusi dengan lancar, mamp bekerja sama, menjadi pendengar yang baik, dan mampu menghargai orang lain. Keterampilan sosial tersebut dibutuhkan untuk menjalin hubungan di rumah, di lingkungan tempat tinggal, dan lingkungan kerja agar terjalin hubungan yang berkualitas (Izzati, 2014).

Auditor internal pemerintah merupakan auditor yang bekerja di instansi pemerintah yang bertugas melakukan pengawasan interen terhadap pelaksanaan urusan pemerintahan di Daerah. Auditor internal melakukan pembinaan atas penyelenggaraan pemerintahan Kabupaten/Kota. Pengawasan dan pembinaan yang dilakukan auditor tentu akan menciptakan interaksi dengan auditeenya. Interaksi atau komunikasi itu terjadi ketika melakukan laporan audit formal, saat tatap muka selama pertemuan atau pemeriksaan, dan melalui berbagai komunikasi formal dan informal lainnya (Noorhuda, 2015).

Auditor internal selalu dalam posisi untuk memberikan rekomendasi atau saran-saran perbaikan dan mengevaluasi kinerja pemerintah. Dengan demikian, terdapat hubungan antara para auditor internal yaitu orang yang melakukan evaluasi dengan orang yang dievaluasi. Ketika saran atau rekomendasi yang diberikan auditor internal tidak benar, terdapat kesalahpahaman, dan terjadi konflik, biasanya hal tersebut akibat dari masalah miscommunication. Jika sudah terjadi miscommunication, maka pokok permasalahan yang ingin disampaikan menjadi tidak terakomodir dengan baik. Situasi demikian dapat menimbulkan konflik antara auditor internal dengan pihak yang diaudit maka dari itu sangat penting seorang auditor internal memiliki keterampilan sosial yang baik (Noorhuda, 2015).

Fenomena adanya konflik antara auditor internal dan auditee terjadi di Pemerintah Daerah Kabupaten Nagekeo. Terdapat pandangan yang berbeda di antara kedua pihak atas kinerja auditor internal terkait independensi, kompetensi, perilaku etis, pelaporan hasil audit dan tindak lanjut audit karena perbedaan faktor-faktor yang mempengaruhi persepsi pada masing-masing pihak. Perbedaan pandangan tersebut adalah bahwa auditor tidak memenuhi harapan auditee. Selain itu ada juga perbedaan pandangan terjadi diantara auditor yang baru di pindah tugaskan dari daerah yang berbeda. Auditor sulit bersosialisasi karena harus beradaptasi dengan lingkungan dan budaya ditempat kerja yang baru. Dalam kondisi seperti ini diperlukan keterampilan sosial yang baik agar segera dapat beradapatasi. Kondisi ini dapat menganggu kinerja auditor yang bersangkutan (Suciati dan Agung Rahmadsyah, 2016).

Pentingnya auditor internal memiliki keterampilan sosial dapat dijelaskan oleh teori FIRO-B (Fundamental Interpersonal Relation Orientation Behaviour). Berdasarkan teori FIRO-B yang dikemukan oleh Schutz tahun 1958 auditor internal harus menyesuaikan diri dengan orang lain dengan tiga dimensi dasar yang harus dimiliki oleh setiap individu, yaitu inclusion, control, dan affection. Teori FIRO-B menghendaki auditor internal untuk memiliki hubungan yang kompatibel atau selaras dengan lingkungan dan masyarakat dimana auditor internal berada serta meninggalkan hal-hal yang berkaitan dengan primordialisme dan etnosentrisme seperti perbedaan budaya, jenis kelamin, dan usia yang bertujuan untuk menghindari konflik, stres, dan frustasi(Bartolini, et al 2014).

Penelitian terkait pentingnya keterampilan sosial telah dilakukan oleh banyak peneliti sebelumnya. Bayou, et al (2014) melakukan penelitian untuk menganalisis perbedaan keterampilan sosial akuntan pada kantor akuntan publik dari beragam budaya. Studi eksplorasi menggunakan FIRO-B. Penelitian dilakukan mengenai preferensi keterampilan sosial personel kantor akuntan internasional dan membandingkannya dengan personel kantor 
akuntan nasional (Amerika Serikat). Hasil studinya menunjukkan bahwa karyawan pada kantor akuntan di Amerika Serikat dengan kantor akuntan di non-Amerika secara signifikan berbeda dalam wanted inclusion, wanted control, dan wanted affection.

Siegel, et al (2015) melakukan penelitian untuk menguji preferensi interaksi sosial personil kantor akuntan regional dan membandingkannya dengan preferensi personil kantor akuntan dengan skala nasional. Studinya menunjukkan bahwa karyawan di kantor akuntan dengan skala regional memiliki nilai interaksi sosial lebih tinggi secara signifikan daripada karyawan di kantor akuntan dengan skala nasional. Pada skala regional juga ditemukan bahwa laki-laki memiliki nilai SII yang jauh lebih tinggi daripada perempuan. Penelitian tersebut menunjukkan bahwa keterampilan sosial juga dipengaruhi oleh perbedaan jenis kelamin. Hasil penelitian ini sejalan dengan penelitian Noorhuda (2015), Siburian (2016), dan penelitian Purwanti (2017).

Penelitian ini berbeda dengan penelitian-penelitian sebelumnya. Penelitian ini mencoba membandingkan keterampilan sosial yang dimiliki auditor internal Pemerintah dari sisi perbedaan budaya, jenis kelamin, dan usia dengan menggunakan alat ukur FIRO-B pada kantor Badan Pengawasan Keuangan dan Pembangunan (BPKP) Perwakilan Provinsi Bengkulu. Penelitian ini penting untuk memahami konsep keterampilan sosial yang harus dimiliki auditor internal dalam berbagai perbedaan budaya, jenis kelamin dan usia dalam meningkatkan kinerja sebagai auditor internal.

Fenomena telah menunjukkan bahwa saat auditor bekerja ditempat kerja yang baru, keterampilan sosialnya jadi menurun. Padahal keterampilan sosial merupakan keterampilan yang tercipta dari potensi, kemampuan dan keinginan yang kuat dari seorang auditor. Jadi seharusnya keterampilan sosial tidak berubah dengan adanya perbedaan budaya, jenis kelamin dan usia. Namun demikian beberapa penelitian telah menemukan terdapat pengaruh antara kemampuan auditor dalam mengaplikasi keterampilan sosialnya terhadap perbedaan budaya, jenis kelamin dan usia. Oleh sebab itu penelitian ini mencoba menguji dari sudut pandang yang berbeda dengan melihat apakah terdapat perbedaan keterampilan sosial atau tidak antara auditor yang memiliki budaya, jenis kelamin dan usia yang berbeda.

\section{KERANGKA TEORITIS DAN HIPOTESIS}

\section{Landasan Teori}

FIRO (Fundamental Interpersonal Relation Orientation) merupakan salah satu teori yang berkaitan dengan hubungan interpersonal yang diperkenalkan oleh Schutz (1958). FIRO secara jelas menetapkan dimana individu harus menyesuaikan diri dengan orang lain dengan tiga dimensi dasar yang harus dimiliki oleh setiap individu, yaitu Inclusion, control, dan affection. Teori FIRO menghendaki Individu untuk memiliki hubungan yang kompatibel atau selaras dengan masyarakat dan lingkungan di mana individu berada serta meninggalkan halhal yang berkaitan dengan primordialisme dan etnosentrisme seperti perbedaan jenis kelamin, usia dan budayayang bertujuan untuk menghindari konflik, stres dan frustasi (Bartolini,et al2014).

\section{Keterampilan Sosial}

Izzati (2014) menyatakan bahwa keterampilan sosial merupakan kemampuan seseorang dalam mengadakan hubungan dengan orang lain dan kemampuan memecahkan masalah, sehingga dapat beradaptasi secara harmonis dengan masyarakat disekitarnya. Keterampilan sosial cukup erat kaitannya dengan berbagai kemampuan lainnya seperti menjalin kerjasama dalam kelompok, berinteraksi dengan sebayanya, bergabung dalam kelompok, menjalin pertemanan baru, menangani konflik, dan belajar bekerja sama. 
Lismawati, Emilyan Inzar dan Jaka Isgiyarta

Keterampilan sosial merupakan kemampuan seseorang untuk berani berbicara, mengungkapkan setiap perasaan atau permasalahan yang dihadapi sekaligus menemukan penyelesaian yang adaptif, memiliki tanggung jawab yang cukup tinggi dalam segala hal, penuh pertimbangan sebelum melakukan sesuatu, mampu menolak dan menyatakan ketidaksetujuannya terhadap pengaruh negativedari lingkungan.

\section{Budaya(Culture)}

Menurut Widiastuti (2017)kebudayaan adalah semua hasil karya manusia dalam rangka kehidupan masyarakat yang dijadikan milik manusia yang diperoleh dengan belajar. Hal ini mengisyaratkan bahwa hampir seluruh tindakan manusia adalah kebudayaan. Budaya akan terus berkembang karena kemapuan manusia untuk belajar sehingga merupakan pola hidup menyeluruh dan bersifat kompleks yang terbentuk dari berbagai unsur yang rumit di antaranya agama, adat istiadat,bahasa, teknologi, kesenian, serta pengetahuan. Dengan demikiankebudayaan lebih dari sekedar kesenian atau adat istiadat saja, tetapi meliputi bidang yang tiadabatas.

Berdasarkan hasil observasi awal yang telah dilakukan oleh peneliti pada tanggal 21Oktober 2018, diketahui bahwa auditor internal di kantor Badan Pengawas Keuangan dan Pembangunan (BPKP) Perwakilan Provinsi Bengkulu mayoritas berasal dari suku Melayu, Jawa,Batak dan Sunda.Penelitian ini membagi budaya menjadi dua yaitu budaya Melayu dan Non Melayu, peneliti membatasi yang di maksud dengan budaya Non Melayu di dalam penelitian ini adalah suku Jawa, Batak dan Sunda.

Menurut Susanti (2017) orang Melayu sangat enerjik dan penuh keinginan kuat untuk maju. Identitas orang Melayu adalah jujur, berani, jarang terlibat dalam aksi kriminal, dan sangat suka kepada tegaknya hukum. Adapun ciri-ciri bangsa Melayu adalah identik dengan agama islam, berpijak kepada yang Esa, Selalu mementingkan penegakan hukum, mengutamakan budi dan bahasa untuk menujukan sopan santun dan tinggi peradabannya, mengutamakan pendidikan serta ilmu, dan sangat menjunjung nilai-nilai budaya.

Menurut Marzuki (2017)karakteristik masyarakat Jawa adalah percaya kepada Tuhan sebagai Sangkan Paraning Dumadi, dengan segala sifat dan kebesaran-Nya, bercorak identitas yaitu percaya kepada sesuatu yang bersifat immateriil (bukan kebendaan) dan halhal yang bersifat adikodrati (supernatural) serta cenderung ke arah mistik, lebih mengutamakan hakikat daripada segi-segi formal dan ritual, mengutamakan cinta kasih sebagai landasan pokok hubungan antar manusia, percaya kepada takdir dan cenderung bersikap pasrah, bersifat konvergen dan universal, momot dan non-sektarian, cenderung pada simbolisme, cenderung pada gotong royong, guyub, rukun, damai, dan kurang kompetitif serta kurang mengutamakan materi.

Menurut Monika (2018) karakteristik masyarakat Batakadalah mengekspresikan emosi dalam bentuk tingkah laku, perkataan atau raut muka disesuaikan pula dengan kuat atau lemahnya emosi yang sedang dirasakan. Tidak melebih-lebihkan juga tidak berusaha menutup-nutupinya, suku Batak dikenal dengan kegigihannya, gaya bicara keras, berani dan bertindak tegas. Oleh karenanya orang Batak lebih suka berterus terang tentang emosi yang sedang dirasakannya.

Menurut Sriwulan (2017) karakteristik Suku sunda adalah mayoritas beragama islam, mempercayai hal-hal yang bersifat magis, menjunjung tinggi adat istiadat bersifat konvergen dan universal, momot dan non-sektarian, cenderung pada simbolisme, cenderung pada gotong royong, guyub, rukun, damai, dan kurang kompetitif serta kurang mengutamakan materi.

\section{Jenis Kelamin (Sex)}

MenurutJati, et al(2017) jenis kelamin adalah perbedaan antara perempuan dan lakilaki secara biologis sejak seseorang lahir. Perbedaan biologis tersebut tidak dapat 
dipertukarkan meskipun dipengaruhi oleh peran sosialnya. Dalam perbedaan jenis kelamin terjadi diferensiasi atau perbedaan peran sosial yang dilekatkan pada laki-laki dan perempuan. Dalam menyesuaikan diri dalam suatu lingkungan baik itu lingkungan kerja, perbedaan jenis kelamin dan peran sosial tersebut diharapkan tidak mempengaruhi keterampilan sosial individu untuk melaksanakan pekerjaan yang baik dengan hubungan yang harmonis bersama orang lain atau dalam hal ini rekan kerjanya.

\section{Usia (Age)}

Menurut Sasongko (2016) umur adalah salah satu faktor level individu yang ikut berpengaruh terhadap profesionalisme auditor. Pola pikir seorang auditor tentunya akan semakin berkembang searah dengan peningkatan rentang kehidupan yang dilalui. Perbedaan usia di dalam organisasi akan sangat wajar terjadi dan kinerja suatu organisasi juga dapat dilihat dari faktor usia tersebut. Biasanya usia yang lebih tua akan lebih berpengalaman, namun bukan berarti yang usianya masih tergolong muda tidak memiliki kemampuan. Auditor senior cenderung akan memiliki kepribadian yang semakin matang dalam hal pengalaman, etika, kebijaksanaan dan komitmen sehingga mampu mengayomi auditor internal junior dalam pekerjaan maupun kehidupan sosial.

Dalam komunikasi faktor usia di dalam organisasi akan semakin bijak seiring dengan pengalaman dan pendidikan yang telah banyak ia lalui. Namun, dalam kinerja umumnya, semakin tua usia individu maka produktivitasnya akan semakin menurun. Dalam auditing (pemeriksaan) matangnya usia auditor tidak akan terlepas dari persepsinya terhadap pemeriksaan, dimana terdapat pilihan bagi auditor untuk cenderung berperilaku menyukai atau menghindari risiko audit yang ada. Ini tentu akan mempengaruhi sikap auditor terhadap auditee dan penerimaannya oleh auditee terhadap sikap auditor. Hal tersebut akan berdampak pada hasil korektif yang dicapai dalam pemeriksaan. Berikut disajikan kerangka konseptual dan pengembangan hipotesis dari penelitian ini.

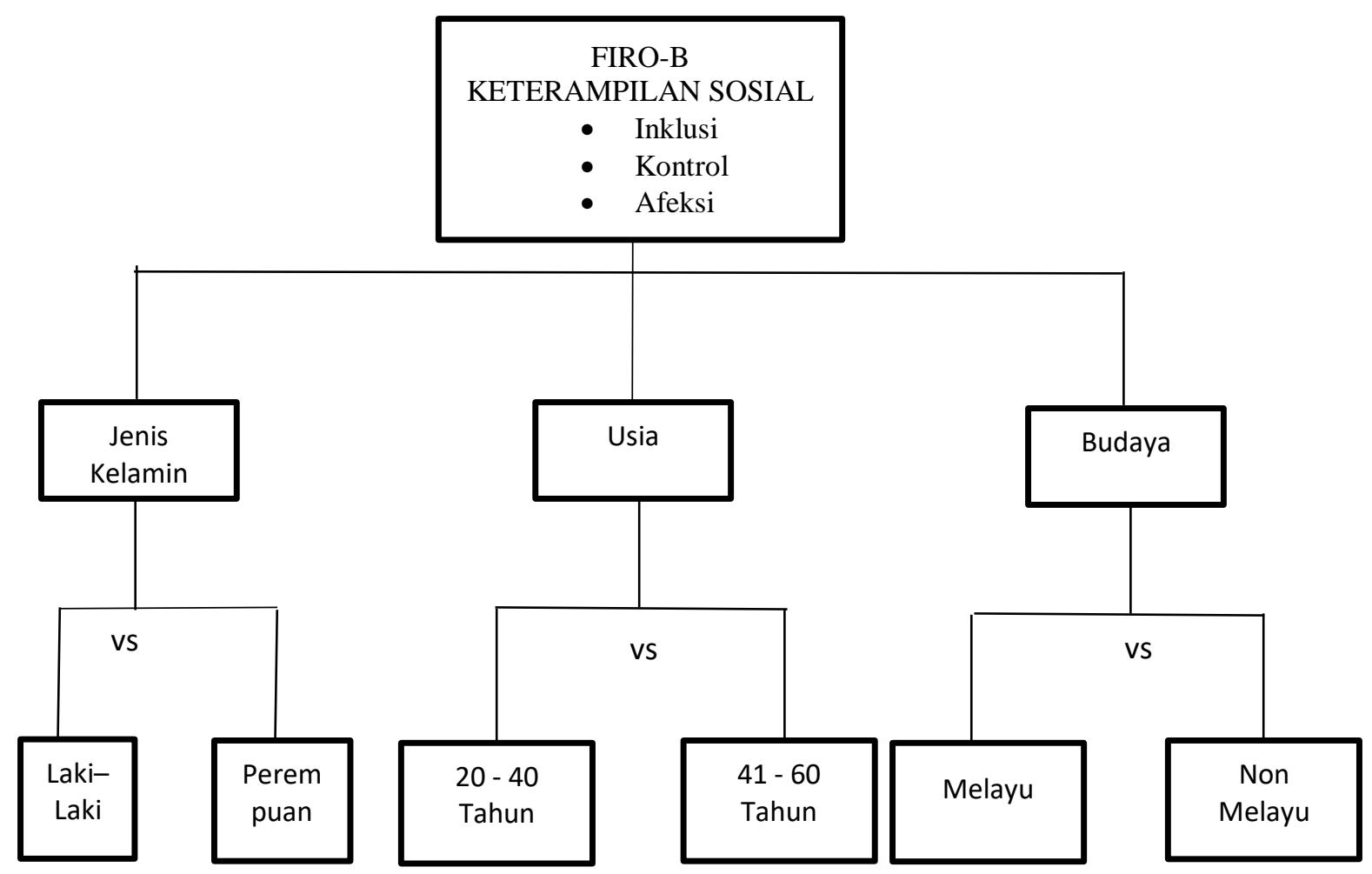

Gambar 1 Kerangka Pemikiran Teoritis 
Menurut Widiastuti (2017) kebudayaan adalah semua hasil karya manusia dalam rangka kehidupan bermasyarakat yang dijadikan milik manusia yang diperoleh dengan belajar. Budaya adalah keadaan yang tercipta dilingkungan tempat kerja yang masing-masing individu dapat beradaptasi dengannya. Setiap individu memiliki cara tersendiri dalam beradaptasi dengan budaya yang ada dengan kemampuan keterampilan sosial yang dimilikinya.

Menurut Jati, et al(2017) jenis kelamin adalah perbedaan antara perempuan dan lakilaki secara biologis sejak seseorang lahir. Perbedaan biologis tersebut tidak dapat dipertukarkan meskipun dipengaruhi oleh peran sosialnya.

Menurut Sasongkodalam Siburian (2016) umur adalah salah satu faktoryang ikut berpengaruh terhadap profesionalisme auditor. Pola pikir seorang auditor tentunya akan semakin berkembang searah dengan peningkatan rentang kehidupan yang dilalui. Perbedaan usia di dalam organisasi akan sangat wajar terjadi dan kinerja suatu organisasi juga dapat dilihat dari faktor usia tersebut. Biasanya usia yang lebih tua akan lebih berpengalaman, namun bukan berarti yang usianya masih tergolong muda tidak memiliki kemampuan.

Hubungan budaya, jenis kelamin dan usia dengan keterampilan sosial dapat dijelaskan dengan teori FIRO-B(Fundamental Interpersonal Relation Orientation Behaviour). Berdasarkan teori teori FIRO-B (Fundamental Interpersonal Relation Orientation Behaviour) individu harus menyesuaikan diri dengan orang lain dengan tiga dimensi dasar yang harus dimiliki oleh setiap individu, yaitu inclusion, control, dan affection. Teori FIRO-B menghendaki individu untuk memiliki hubungan yang kompatibel atau selaras dengan lingkungan dan masyarakat di mana individu berada serta meninggalkan hal-hal yang berkaitan dengan primordialisme dan etnosentrisme seperti perbedaan budaya, jenis kelamin, dan usia yang bertujuan untuk menghindari konflik, stres, dan frustasi (Bartolini, et al 2014).

Peneliti-peneliti terdahulu sudah melakukan penelitian terhadap perbedaan keterampilan sosial yang mencakup inklusi, kontrol, dan afeksi yang di pengaruhi faktor budaya seperti pada Purwanti (2017) melakukan penelitian untuk menguji perbedaan tingkat keterampilan sosial antar auditor internal dari latar belakang budaya yang berbeda di Inspektorat Bengkulu Selatan, hasil pengujian membuktikan bahwa tidak terdapat perbedaan signifikan tingkat keterampilan sosial antara auditor internal dari latar belakang budaya Melayu dengan auditor internal dari latar belakang budaya Non Melayu. Selanjutnya penelitian Siburian (2016) membuktikan bahwa keterampilan sosial antara auditor laki-laki dan perempuan tidak terdapat perbedaan yang signifikan. Begitu juga dengan usia, tidak terdapat perbedaan keterampilan sosial antara usia yang berbeda (Siburian, 2016). Berdasarkan uraian diatas dapat diajukan beberapa hipotesis sebagai berikut:

$\mathrm{H}_{1}$ : Tidak terdapat perbedaan keterampilan sosial auditor internal yang memiliki latar belakang budaya Melayu dan Non Melayu pada kantor Badan Pengawasan Keuangan dan Pembangunan (BPKP) Perwakilan Provinsi Bengkulu.

$\mathrm{H}_{2}$ : Tidak terdapat perbedaantingkat keterampilan sosial auditor internalyang berjenis kelamin laki-laki dan perempuan pada kantor Badan Pengawasan Keuangan dan Pembangunan (BPKP) Perwakilan Provinsi Bengkulu.

$\mathrm{H}_{3}$ : Tidak terdapat perbedaan tingkat keterampilan sosial auditor internal yang berusia 2040 tahun dan41-60 tahun pada kantor Badan Pengawasan Keuangan dan Pembangunan (BPKP) Perwakilan Provinsi Bengkulu.

\section{METODE PENELITIAN}

Jenis dan Sumber Data Penelitian

Jenis penelitian ini adalah penelitian kuantitatif dengan menggunakan data primer. Sumber data primer diperoleh dari jawaban responden terhadap survey yang dibagikan dalam 
bentuk kuesioner. Kuesioner dibagikan secara langsung dengan mendatangi tempat responden bekerja.

Populasi dan Sampel

Populasi penelitian ini adalah auditor internal pemerintah yang bekerja di kantor BPKP ( Badan Pengawasan Keuangan Pemerintah) Provinsi Bengkulu. Teknik pengambilan sampel yang digunakan dalam penelitian ini adalah sensus sehingga sampel penelitian ini adalah seluruh anggota populasi yaitu seluruh auditor internal yang ada di pemerintah daerah

Definisi Operasional dan Pengukuran Variabel

Variabel yang digunakan dalam penelitian ini terdiri dari variabel keterampilan sosial, keragaman budaya, jenis kelamin dan usia. Berikut disajikan tabel 1 tentang variabel, definisinya dan indikator pengukuran.

Tabel 1. Definisi Operasional Variabel

\begin{tabular}{|c|c|c|c|}
\hline No & Variabel & Definisi Operasional & Indikator \\
\hline 1 & Keterampilan sosial & $\begin{array}{l}\text { Kemampuan seseorang dalam mengadakan } \\
\text { hubungan dengan orang lain dan } \\
\text { kemampuan memecahkan masalah, } \\
\text { sehingga dapat beradaptasi secara } \\
\text { harmonis dengan masyarakat disekitarnya }\end{array}$ & $\begin{array}{l}\text { Menggunakan instrumen } \\
\text { FIRO-B yaitu inclusion, } \\
\text { control,dan affection }\end{array}$ \\
\hline 2 & Budaya & $\begin{array}{l}\text { Hasil karya manusia dalam rangka } \\
\text { kehidupan bermasyarakat yang dijadikan } \\
\text { milik manusia yang diperoleh dengan } \\
\text { belajar }\end{array}$ & $\begin{array}{l}\text { 1. Budaya Melayu } \\
\text { 2. Budaya Non Melayu }\end{array}$ \\
\hline 3 & Jenis Kelamin & $\begin{array}{l}\text { Perbedaan antara perempuan dan laki-laki } \\
\text { secara biologis sejak seseorang lahir }\end{array}$ & $\begin{array}{l}\text { 1. Laki-laki } \\
\text { 2. Perempuan }\end{array}$ \\
\hline 4 & Usia & Durasi waktu auditor internal hidup & $\begin{array}{l}\text { 1. Auditor internal usia } 20 \\
\text { hingga } 40 \text { tahun } \\
\text { 2. Auditor internal usia } 41 \\
\text { hingga } 60 \text { tahun }\end{array}$ \\
\hline
\end{tabular}

Sumber: Diolah dalam penelitian 2020.

\section{Teknik Analisis Data}

Metode analisis data menggunakan skor FIRO-B dan Uji Beda (Independent-Sample $t$-Test) dengan SPSS. Nilai jawaban setiap pernyataan kuesioner adalah antara 0 dan 1. Jadi jumlah maksimal yang bisa didapatkan untuk setiap aspek perilaku Expressed Inclusion (EI), Wanted Inclusion (WA), Expressed Control (EC), Wanted Control (WC), Expressed Affection (EA), Wanted Affection (WA) berkisar antara 0 hingga 9, sehingga nilai SII berkisar antara 0 hingga 54. Setiap pernyataan memiliki standar nilai yang berbeda-beda. Rumus dari setiap aspek perilaku tersebut yaitu:

1) Total Inclusion (Inklusi)

Mengacu pada perasaan individu tentang diri sendiri, yang dihitung dengan rumus:

Total inclusion $=$ Expressed Inclusion + Wanted Inclusion

2) Total Control (Kontrol)

Kebutuhan untuk menguasai dan mempengaruhi, dihitung dengan rumus:

Total control $=$ Expressed Control + Wanted Control

3) Total Affection (Afeksi)

Kebutuhan akan persahabatan dan keakraban, dihitung dengan rumus:

Total Affection = Expressed Affection + Wanted Affection 
ANALISIS KETERAMPILAN SOSIAL MENGGUNAKAN FIRO-B PADA AUDITOR INTERNAL PEMERINTAH DI PROVINSI BENGKULU

Lismawati, Emilyan Inzar dan Jaka Isgiyarta

4) TotalSII (Social Interaction Index)

SII= Total Inclusion+ Total Control + Total Affection

\section{HASIL DAN PEMBAHASAN}

Berdasarkan data hasil pengembalian kuesioner, diperoleh karakteristik FIRO-B berdasarkan komponennya (inclusion, control, dan affection) beserta subkomponennya (Expressed dan Wanted) yang dapat dilihat dari tabel dan penjelasan sebagai berikut:

\section{Karakteristik FIRO-B Berdasarkan Budaya}

Dari hasil perhitungan FIRO-B berdasarkan budaya, diperoleh karakteristik yang dapat dilihat pada tabel berikut:

Tabel 1. Karakteristik FIRO-B Budaya

\begin{tabular}{lcc}
\hline \multirow{2}{*}{ Karakteristik FIRO-B } & \multicolumn{2}{c}{ Budaya } \\
\cline { 2 - 3 } & Melayu & NonMelayu \\
\hline Expressed Inclusion (EI) & 3,56 & 3,24 \\
\hline Wanted Inclusion (WI) & 5,38 & 4,90 \\
\hline Inclusion $(\mathbf{I})$ & $\mathbf{8 , 9 4}$ & $\mathbf{8 , 1 4}$ \\
\hline Expressed Control (EC) & 2,81 & 2,86 \\
\hline Wanted Control (WC) & 6,31 & 4,33 \\
\hline \multicolumn{1}{c}{ Control $(\boldsymbol{C})$} & $\mathbf{9 , 1 3}$ & $\mathbf{7 , 1 9}$ \\
\hline Expressed Affection (EA) & 2,13 & 3,05 \\
\hline Wanted Affection (WA) & 2,25 & 1,86 \\
\hline \multicolumn{1}{c}{ Affection $(\mathbf{A})$} & $\mathbf{4 , 3 8}$ & $\mathbf{4 , 9 0}$
\end{tabular}

Kekuatan kebutuhan interpersonal auditor internal dapat dilihat dari total nilai kebutuhan inklusi, nilai kontrol, dan nilai afeksi. Apabila nilai inklusi, kontrol, dan afeksi berkisar di angka 0-5 hal ini berarti tingkat kebutuhan interpersonal auditor internal adalah rendah. Apabila nilai inklusi, kontrol, dan afeksi auditor internal berada di 6-12 hal ini berarti tingkat kebutuhan interpersonal auditor internal adalah sedang, dan apabila nilai total inklusi, kontrol, dan afeksi berada di kisaran 13-18 hal ini berarti tingkat kebutuhan interpersonal auditor internal adalah tinggi (Sarwono,2015).

Berdasarkan tabel 1 dapat disimpulkan bahwa total kebutuhan inklusi pada kelompok auditor internal yang berbudaya Melayu ialah 8,94 sedangkan kelompok auditor internal yang berbudaya Non Melayu memiliki total kebutuhan inklusi senilai 8,14. Total tersebut menunjukkan bahwa dari rata-rata total kebutuhan inklusi, nilai yang lebih tinggi ialah pada kelompok budaya Melayu. Ini berarti, auditor internal dari budaya Melayu memiliki kebutuhan interpersonal untuk merasa dihargai lebih tinggi daripada auditor internal dari budaya NonMelayu. Namun secara total kebutuhan Inklusi auditor internal yang berbudaya Melayu maupun yang berbudaya Non Melayu tidak memiliki selisih yang besar atau berada di kisaran sedang yakni kisaran 6-12.

Auditor internal yang berbudaya Melayu juga memiliki total nilai yang lebih tinggi dibandingkan dengan budaya Non Melayu pada kebutuhan kontrol. Hal ini menunjukkan bahwa auditor internal yang berbudaya Melayu lebih tinggi dalam kebutuhan untuk menguasai dan mempengaruhi dalam hubungan interpersonal. Pada tabel 1 terlihat bahwa nilai kebutuhan kontrol auditor internal yang berbudaya Melayu sebesar 9,13 sedangkan nilai kebutuhan kontrol auditor internal yang berbudaya Non Melayu hanya sebesar 7,19.Namun secara total kebutuhan kontrol auditor internal yang berbudaya Melayu maupun yang 
berbudaya Non Melayu tidak memiliki selisih yang besar atau berada di kisaran sedang yakni kisaran 6-12.

Berdasarkan kebutuhan afeksi, auditor internal dari budaya Non Melayu memiliki tingkat kebutuhan interpersonal lebih tinggi daripada auditor internal dari budaya Melayu, yaitu sebesar 4,90 dan total nilai tersebut tidak berbeda jauh dengan total nilai dari kelompok budaya Melayu, yaitu sebesar 4,38. Ini berarti auditor internal yang berasal dari budaya Non Melayu lebih tinggi tingkat kebutuhan interpersonalnya akan persahabatan dan keakraban, yaitu kebutuhan untuk merasa dekat dengan orang lain. Namun secara total kebutuhan afeksi auditor internal yang berbudaya Melayu maupun yang berbudaya Non Melayu tidak memiliki selisih yang besar dan berada di kisaran rendah yakni kisaran 0-5.

\section{Karakteristik FIRO-B Berdasarkan Jenis Kelamin}

Dari hasil perhitungan FIRO-B berdasarkan jenis kelamin, diperoleh karakteristik yang dapat dilihat pada tabel berikut:

Tabel 2. Karakteristik FIRO-B Jenis Kelamin

\begin{tabular}{lcc}
\hline \multirow{2}{*}{ Karakteristik FIRO-B } & \multicolumn{2}{c}{ Jenis Kelamin } \\
\cline { 2 - 3 } & Laki-laki & Perempuan \\
\hline Expressed Inclusion (EI) & 3,40 & 3,71 \\
\hline Wanted Inclusion (WI) & 4,55 & 3,71 \\
\hline Inclusion $(\boldsymbol{I})$ & $\mathbf{7 , 9 5}$ & $\mathbf{7 , 4 1}$ \\
\hline Expressed Control $(\mathrm{EC})$ & 3,15 & 2,18 \\
\hline Wanted Control $(\mathrm{WC})$ & 4,15 & 6,94 \\
\hline Control $(\boldsymbol{C})$ & $\mathbf{7 , 3 0}$ & $\mathbf{9 , 1 2}$ \\
\hline Expressed Affection (EA) & 3,30 & 1,88 \\
\hline Wanted Affection $(\mathrm{WA})$ & 2,55 & 2,35 \\
\hline \multicolumn{1}{c}{ Affection $(\mathbf{A})$} & $\mathbf{5 , 8 5}$ & $\mathbf{4 , 2 4}$
\end{tabular}

Sumber: Data primer diolah, 2020

Berdasarkan tabel 2 dapat disimpulkan bahwa total kebutuhan inklusi pada kelompok auditor internal yang berjenis kelamin laki-laki ialah 7,95 sedangkan kelompok auditor internal yang berjenis kelamin perempuan adalah 7,41. Total tersebut menunjukkan bahwa dari rata-rata total kebutuhan inklusi, nilai yang lebih tinggi ialah pada kelompok auditor internal yang berjenis kelamin laki-laki. Hal Ini berarti, auditor internal berjenis kelamin lakilakimemiliki kebutuhan interpersonal untuk merasa dihargai lebih tinggi daripada auditor internalyang berjenis kelamin perempuan. Namun secara total kebutuhan inklusi auditor internal yang berjenis kelamin laki-laki maupun auditor internalyang berjenis kelamin perempuan tidak memiliki selisih yang besar dan berada di kisaran sedang yakni kisaran 612.

Kebutuhan kontrol auditor internal yang berjenis kelamin perempuan memiliki total nilai yang lebih tinggi dibandingkan dengan auditor internal yang berjenis kelamin laki-laki. Hal ini menunjukkan bahwa auditor internal yang berjenis kelamin perempuan lebih tinggikebutuhan untuk menguasai dan mempengaruhi dalam hubungan interpersonal. Pada 4.5terlihat bahwa nilai kebutuhan kontrol auditor internal yang berjenis kelamin perempuan adalah 9,12 sedangkan nilai kebutuhan kontrol auditor internal yang berjenis kelamin lakilaki adalah 7,30. Namun secara total kebutuhan kontrol auditor internal yang berjenis kelamin laki-laki maupun yang berjenis kelamin perempuan tidak memiliki selisih yang besar dan berada di kisaran sedang yakni kisaran 6-12.

Kebutuhan afeksi auditor internalyang berjenis kelamin laki-laki memiliki tingkat kebutuhan interpersonal lebih tinggi daripada auditor internal yang berjenis kelamin perempuan, yaitu sebesar 5,85 dan total nilai tersebut tidak berbeda jauh dengan total nilai 
dari auditor internal yang berjenis kelamin perempuan, yaitu sebesar 4,24. Ini berarti auditor internalyang berjenis kelamin laki-laki lebih tinggi tingkat kebutuhan interpersonalnya akan persahabatan dan keakraban, yaitu kebutuhan untuk merasa dekat dengan orang lain. Namun secara total kebutuhan afeksi auditor internal yang berjenis kelamin laki-laki maupun yang berjenis kelamin perempuan tidak memiliki selisih nilai total yang besar dan berada di kisaran sedang untuk auditor internal yang berjenis kelamin laki-laki penulis membulatkan 5,85 menjadi 6 sehingga berada di kisaran 6-12 sedangkan auditor internal yang berjenis kelamin perempuan tingkat kebutuhan afeksi adalah rendah karena berada di kisaran 1-5.

\section{Karakteristik FIRO-B Berdasarkan Usia}

Dari hasil perhitungan FIRO-B berdasarkan usia, diperoleh karakteristik yang dapat dilihat pada tabel di bawah ini:

Tabel 3. Karakteristik FIRO-B Usia

\begin{tabular}{lcc}
\hline \multirow{2}{*}{ Karakteristik FIRO-B } & \multicolumn{2}{c}{ Usia } \\
\cline { 2 - 3 } & $\mathbf{2 0 - 4 0}$ tahun & $\mathbf{4 1 - 6 0 ~ t a h u n ~}$ \\
\hline Expressed Inclusion (EI) & 3,11 & 4,06 \\
\hline Wanted Inclusion (WI) & 4,26 & 4,00 \\
\hline Inclusion $(\boldsymbol{I})$ & $\mathbf{7 , 3 7}$ & $\mathbf{8 , 0 6}$ \\
\hline Expressed Control (EC) & 2,89 & 1,61 \\
\hline Wanted Control (WC) & 4,63 & 6,11 \\
\hline Control $(\boldsymbol{C})$ & $\mathbf{7 , 5 3}$ & $\mathbf{7 , 7 2}$ \\
\hline Expressed Affection (EA) & 2,74 & 2,50 \\
\hline Wanted Affection (WA) & 1,53 & 1,17 \\
\hline Affection $(\mathbf{A})$ & $\mathbf{4 , 2 6}$ & $\mathbf{3 , 6 7}$ \\
\hline Sumber: Data primer diolah, 2020 & &
\end{tabular}

Berdasarkan 3 dapat disimpulkan bahwaauditor internal yang berusia 41-60 tahun memiliki kebutuhan inklusi yang lebih tinggi dibandingkan dengan auditorinternal yang berusia 20-40 tahundan ini menunjukkan bahwa auditor internal berusia 41-60 tahun memiliki kebutuhan untuk dilibatkan dalam penugasan atau dilibatkan dalam interaksi sosial yang lebih tinggi dari auditor internal berusia 20-40 tahun. Hal tersebut terlihat dari total nilai inklusi auditor berusia 20-40 tahun sebesar 7,37 dan auditor internal berusia 41-60 tahun sebesar 8,06. Namun secara total kebutuhan inklusi auditor internal yang 20-40 tahun maupun yang 41-60 tahun tidak memiliki selisih yang besar dan berada di kisaran sedang yakni kisaran 6-12.

Kebutuhan kontrol auditor internal berusia 41-60 tahun memiliki total nilai yang lebih tinggi dibandingkan dengan auditor internal berusia 20-40 tahun, auditor internal yang berusia 41-60 tahun memiliki nilai kontrol sebesar 7,72 dan auditor internal yang berusia 2040 memiliki nilai kontrol 7,53. Ini berarti auditor internal berusia 41-60 tahun memiliki kebutuhan untuk menguasai atau mempengaruhi dalam hubungan sosial yang lebih tinggi dibanding auditor internal berusia 20-40 tahun. Namun secara total kebutuhan kontrol auditor internal yang berusia 20-40 tahun maupun yang berusia 41-60 tahun tidak memiliki selisih yang besar dan berada di kisaran sedang yakni kisaran 6-12.

Kebutuhan afeksiauditor internal berusia 20-40 tahun memiliki nilai yang lebih tinggi dibandingkan dengan auditor berusia 41-60 tahun, yaitu sebesar 4,26 untuk auditor berusia 20-40 tahun dan 3,67 untuk auditor internal berusia 41-60 tahun. Hal tersebut juga menunjukkan bahwa antara dua golongan usia yang berbeda tersebut memiliki tingkat kebutuhan interpersonal yang juga berbeda. Auditor internal yang berusia 20-40 tahun memiliki kebutuhan akan keakraban yang lebih tinggi dibandingan dengan auditor berusia 41-60 tahundan total nilai kebutuhan tersebut berkisar antara 0-5 yang menunjukkan bahwa tingkat kebutuhan interpersonal auditor internaladalah sedang. 


\section{Hasil uji hipotesis 1}

Hasil uji hipotesis 1 sebagai berikut :

Tabel 4 Hasil Uji Independent Sample T-Test Budaya

\begin{tabular}{c|c}
\hline Keterangan & Signifikansi \\
\hline SII & 0,482 \\
Inclusion Needed & 0,563 \\
Control Needed & 0,110 \\
Affection Needed & 0,628 \\
\hline
\end{tabular}

Sumber: Data primer diolah, 2020

Berdasarkan tabel 4 dapat disimpulkan bahwa hipotesis pertama diterima. Hal ini ditunjukkan dari hasil pengujian sebesar 0,482 yang berarti 0,482>0,05. Ini berarti tidak terdapat perbedaan tingkat keterampilan sosial auditor internal berbudaya Melayu dan Non Melayu pada Kantor Badan Pengawasan Keuangan dan Pembangunan (BPKP) Perwakilan Provinsi Bengkulu. Tidak adanya perbedaan tingkat keterampilan sosial auditor internal dengan budaya yang beda disebabkan auditor internal memiliki keinginan untuk saling berinteraksi dan rasa untuk saling memiliki yang tinggi. Hal ini terlihat dari adanya keingian untuk terlibat dalam kegiatan audit, terlibat dalam organisasi sosial, menjaga hubungan baik dengan rekan profesi, dan menghindari kondisi kesendirian.

Tidak adanya perbedaan tingkat keterampilan sosial auditor internal yang berbudaya Melayu dan Non Melayu juga akan berakibat terhindarnya auditor internal dari masalahmasalah miscommunication(kesalahpahaman) yang pada akhirnya dapat mendorong konflik dengan pihak auditee maupun sesama auditor internal ketika melaksanakan kegiatan audit.

Hasil penelitian ini sejalan dengan teori teori FIRO-B (Fundamental Interpersonal Relation Orientation Behaviour). Teori FIRO-B menghendaki auditor internal untuk memiliki hubungan yang baik serta harmonis dengan lingkungan dan masyarakat dimana auditor internal berada. Hasil penelitian ini konsisten dengan penelitian Purwanti (2017) yang menunjukkan tidak terdapat perbedaan signifikan tingkat keterampilan sosial antara auditor internal dari latar belakang budaya Melayu dengan auditor internal dari latar belakang budaya Non Melayu. Tetapi dalam rata-rata skor FIRO-B, nilai rata-rata SII auditor internal dari budaya Non Melayu lebih tinggi daripada nilai rata-rata SII auditor internal dari budaya Melayu.

\section{Hasil uji hipotesis}

Tabel 5. Hasil Uji Independent Sample T-TestJenis Kelamin

\begin{tabular}{c|c}
\multicolumn{2}{c}{ Kelamin } \\
\hline Keterangan & Signifikansi \\
\hline SII & 0,916 \\
\hline Inclusion Needed & 0,661 \\
\hline Control Needed & 0,136 \\
\hline Affection Needed & 0,185
\end{tabular}

Sumber: Data primer diolah, 2020

Berdasarkan tabel 5 dapat disimpulkan bahwa hipotesis kedua diterima. Hal ini ditunjukkan dari hasil pengujian sebesar 0,916 yang berarti 0,916>0,05. Ini berarti tidak terdapat perbedaan tingkat keterampilan sosial auditor internal dengan jenis kelamin yang berbeda pada Kantor Badan Pengawasan Keuangan dan Pembangunan (BPKP) Perwakilan Provinsi Bengkulu. 
Tidak adanya perbedaan tingkat keterampilan sosial auditor internal yang berjenis kelamin laki-laki dan perempuan disebabkan auditor internal memiliki standar dan kode etik profesi yang sama yaitu peraturan Nomor: KEP-005/AAIPI/DPN/2014 yang mengatur perilaku auditor internal agar mampu menyesuaikan diri dengan lingkungan dan pekerjaan. Standar dan kode etik ini adalah landasan auditor internal untuk mampu bekerja dengan baik serta harmonis baik dengan sesama rekan kerja maupun auditee(Safuan, 2017). Hal ini sejalan dengan teori FIRO-B.

Hasil penelitian ini konsisten dengan penelitian yang dilakukan oleh Siburian (2016) yang melakukan penelitian di kantor Badan Pengawasan Keuangan dan Pembangunan (BPKP) Provinsi Bengkulu yang menunjukkan bahwa tidak terdapat perbedaan yang signifikan tingkat keterampilan sosial auditor internal laki-laki dengan perempuan.

\section{Hasil uji hipotesis 3}

Tabel 6 Hasil Uji Independent Sample T-Test Usia

\begin{tabular}{c|c}
\hline Keterangan & Signifikansi \\
\hline SII & 0,925 \\
Inclusion Needed & 0,589 \\
Control Needed & 0,873 \\
Affection Needed & 0,561 \\
\hline
\end{tabular}

Sumber: Data primer diolah, 2020

Berdasarkan tabel 6 dapat disimpulkan bahwa hipotesis tiga diterima. Hal ini ditunjukkan dari hasil pengujian sebesar 0,925 yang berarti 0,925 >0,05. Ini berarti tidak terdapat perbedaan keterampilan sosial auditor internal berdasarkan usia, pada Kantor Badan Pengawasan Keuangan dan Pembangunan (BPKP) Perwakilan Provinsi Bengkulu.

Auditor internal sama-sama memiliki keinginan untuk menjaga keakraban dan persahabatan. Hal ini terlihat dari adanya keinginan auditor internal untuk menjaga hubungan baik dengan auditee dan rekan profesi. Hasil penelitian ini sejalan dengan teori FIRO-B.

Hasil pengujian hipotesis dalam penelitian ini konsisten dengan penelitian yang dilakukan Siburian (2016) yang membuktikan bahwa tidak terdapat perbedaan yang signifikan tingkat keterampilan sosial antara auditor yang tua dan auditor yang muda.

\section{PENUTUP}

Berdasarkan tujuan penelitian yang telah dipaparkan, maka dapat dibuat kesimpulan bahwa tidak ada perbedaan tingkat keterampilan sosial antara auditor yang memiliki budaya, jenis kelamin dan usia berbeda pada kantor Badan Pengawasan Keuangan dan Pembangunan (BPKP) Perwakilan Provinsi.

Implikasi penelitian ini adalah secara teoritis, hasi penelitian ini mendukung teori FIRO-B (Fundamental Interpersonal Relation Orientation Behaviour) yang menyatakan bahwa auditor internal harus memiliki hubungan yang kompatibel serta meninggalkan hal-hal yang terkait dengan perbedaan primordialisme dan etnosentrisme seperti perbedaan budaya, jenis kelamin, dan usia.

Secara praktis, hasil penelitian ini memberikan masukan bagi auditor internal yang berbeda budaya, jenis kelamin, dan usia agar lebih meningkatkan keterampilan sosial dan menjaga keharmonisan dalam organisasi atau lingkungan kerja. Bagi Badan Pengawasan Keuangan dan Pembangunan (BPKP) dapat dijadikan sebagai acuan dalam meningkatkan keterampilan sosial antar sesama anggota untuk mencapai kinerja yang baik dan harmonis di 
dalam lingkungan kerja, serta melakukan seleksi calon auditor internal dengan mengutamakan auditor internal yang memiliki tingkat keterampilan sosial yang tinggi.

Keterbatasan yang ditemukan dalam penelitian ini adalah instrumen penelitian tidak menyebutkan dengan jelas pembagian suku responden sehingga penelitian ini mengelompokkan suku responden secara subjektif. Responden rate masih rendah, karena ketidak tepatan waktu penyebaran kuesioner dan penggunaan media kuesioner yang terbatas. Bagi penelitian selanjutnya diharapkan menambah penggolongan suku responden pada instrumen penelitian sehingga penggolongan suku responden tidak lagi subjektif. Peneliti selanjutnya diharapkan dapat meningkatkan responden rate dengan memperhatikan waktu penyebaran kuesioner dan penggunaan beberapa media penyebaran kuesioner biar efektif.

\section{DAFTAR PUSTAKA}

Agoes, Sukrisno. (2017). Auditing (Pemeriksaan Akuntan) oleh Kantor Akuntan Publik. Jakarta: Lembaga Penerbit Fakultas Ekonomi Universitas Indonesia.

Bayou, M.E, Siegel, P dan Smith, J. (2014). Social Skill Differences Among CPA Firm Personel of Different Cultures: An Exploratory Study Using the FIRO-B. International Journal of Applied Management, 2(3).

Bartolini, et al. (2014). The Social Skill Preferences Of Tax Professionals In CPA Firms: A FIRO-B Analysis. Journal of Applied Business Research. 26(2): 105-114.

Ghozali, Imam. (2014). Aplikasi Analisis Multivarite dengan SPSS. Semarang: Badan Penerbit Universitas Diponegoro.

Izzati,Nurma.(2014). Pengaruh Keterampilan Sosial Terhadap KemampuanKomunikasi Matematis Mahasiswa. Jurnal Edueksos. 3(1), Januari-Juni 2014.

Jati, Yoenanto, (2017). Kecerdasan Emosional Siswa Sekolah Menengah Pertama Ditinjau Dari Faktor Demografi. Jurnal Psikologi Pendidikan dan Perkembangan. 2(2), Agustus 2013.

Marzuki. (2017). Tradisi dan Budaya Masyarakat Jawa dalam Persfektif Islam. Jurnal Ilmu Sosial Universitas Negeri Yogyakarta.

Monika. (2018).Identitas Budaya pada Mahasiswa Batak Toba. Jurnal Psikologi Ulayat. 2(1).

Norhuda, Endra. (2015). Preferensi Keterampilan Sosial Auditor Internal dengan Menggunakan FIRO-B pada Inspektorat Jenderal Kementerian Keuangan. Skripsi diterbitkan, Jakarta: Program Akuntansi Ekstensi UI.

Purwanti, Elva. (2017). Preferensi Keterampilan Sosial Antar Auditor Internal dari Berbagai Budaya Dengan Menggunakan FIRO-B. Skripsi. Bengkulu : Fakultas Ekonomi dan Bisnis Universitas Bengkulu.

Permenpan Nomor PER/05/M.PAN./03/2008. Tentang Standar Audit Aparat Pengawasan Intern Pemerintah. 2008. Jakarta.

Siburian, Monika Sisilia. 2016. Preferensi Social Skills antara Auditor internal Pemerintah dengan Menggunakan FIRO-B pada Perwakilan BPKP Provinsi Bengkulu.

Skripsi. Bengkulu: Fakultas Ekonomi dan Bisnis Universitas Bengkulu.

Sarwono, S.W. (2015). Psikologi Sosial Individu \& Teori Psikologi Sosial. Jakarta : Balai Pustaka.

Siegel, P. and Schultz, T., (2014). Social Skills Preferences Among Internal Auditors - An Explanatory Study Using FIRO-B. Journal of Applied Business Research; 27(3) ABI/INFORM Global pg. 43 
ANALISIS KETERAMPILAN SOSIAL MENGGUNAKAN FIRO-B PADA AUDITOR INTERNAL PEMERINTAH DI PROVINSI BENGKULU

Lismawati, Emilyan Inzar dan Jaka Isgiyarta

Siegel, P. and Smith, J., (2015). CPA Firm Personnel Preferences For Social Interaction: An

Examination Using The FIRO-B. Journal of Business and Entrepreneurship .15(A2)

(Oct 2003): 77-96. 60 Universitas Indonesia

Safuan. (2017). Internal Auditor. Jakarta: Alfabeta.

Sugiyono, (2014). Metode Penelitian Kuantitatif Kualitatif dan $R \& D$. Bandung: Alfabeta.

Sasongko, J. (2016). Teori Psikologi Sosial. Jakarta: Balai Pustaka.

Susanti, Emilia. (2017). Budaya Malu Cerminan Bagi Perempuan Melayu. Jurnal Sosial dan Budaya. 11(2).

Sriwulan, Yekti. (2017). Kebudayaan Suku Sunda. Skripsi. Yogyakarta: Fakultas Ilmu Sosial dan Ekonomi Universitas Negeri Yogyakarta.

Tuanakotta, (2015). Audit Kontemporer. Jakarta: Salemba Empat. 